\title{
Durable Antibacterial Finishing on Organic Cotton by Inclusion of Thymol into Cyclodextrin Derivative
}

\author{
M. SUNDRARAJAN *AND A. RUKMANI \\ Department of Industrial Chemistry, School of Chemistry, Alagappa University, \\ Karaikudi-3, Tamil Nadu, \\ *Corresponding author Tel/ Fax: +91 9444496151/+91-04565 225202 \\ drmsgreenchemistrylab@gmail.com
}

Received 17 September 2011; Accepted 13 November 2011

\begin{abstract}
Antibacterial finish was done on organic cotton by incorporation of thymol into monochlorotriazinyl- $\beta$-cyclodextrin. Fabric was modified with cyclodextrin derivative in alkaline condition. UV-Visible and FT-IR studies confirmed the presence of cyclodextrin derivative and thymol on modified fabric. The level of thymol entrapped into the fabric was determined quantitatively by HPLC analysis. Agar diffusion test was carried for unwashed and washed fabric against gram positive (S.aureus) and gram negative (E.coli) bacteria. The investigation revealed that modification of fabric with monochlorotriazinyl- $\beta$-cyclodextrin retained the antibacterial property even after 10 washing process.
\end{abstract}

Keywords: Antibacterial, Monochlorotriazinyl- $\beta$-cyclodextrin, Thymol.

\section{Introduction}

Antibacterial finishing is necessary criterion to minimize the microbial growth on textiles. Recently monochlorotriazinyl- $\beta$-cyclodextrin (MCT- $\beta-\mathrm{CD})$ is focusing much attention for durable finishing due to their covalent bond formation ability with fabric. It has no irritating or sensitizing effect and also an efficient tool for surface modification of textile ${ }^{1-3}$. Cyclodextrins are cyclic oligomers which has six $(\alpha)$, seven $(\beta)$ and eight $(\gamma)$ glucose units linked by 1, 4- $\alpha$ - glucosidic bonds. The inclusion complex formation capability of cyclodextrin can be applied to vast area of application such as deodorant, aroma, antimicrobial, insect, mite repellent finishing and UV protection in textiles ${ }^{4-12}$. The major advantage in the formation of antimicrobial agents as inclusion complex is that it produces long lasting biocide action ${ }^{13,14}$.

This study describes the inclusion of thymol into MCT- $\beta-C D$ grafted organic cotton. Antibacterial agent thymol is a monoterpene occurs in oreganos and thymes and used as flavoring agent, antimicrobial, antioxidant and antiseptic agent ${ }^{15}$. MCT- $\beta$-CD is fixed in alkaline condition and the yield was assessed from weight gain of the fabric. UV and FT-IR studies were done to confirm the bonding of MCT- $\beta-C D$ with fabric and the presence of thymol as inclusion complex. HPLC studies were carried to determine thymol level on fabrics. Antibacterial properties were studied against S.aureus (+ve) and E.coli (-ve) under 
unwashed and washed conditions. It has been observed that inclusion of thymol into MCT$\beta$-CD modified fabric facilitated to retain the biocide action even after 10 cycles of washing.

\section{Experimental}

Materials

Organic cotton was purchased from Tirupur Textile Industries Ltd, India. CAVASOL W7 MCT (MCT- $\beta-C D)$ was purchased from Wacker - Chemie Ltd, Bangalore. Sodium carbonate and thymol were obtained from Merck, India. De-ionized water was used.

\section{Apparatus}

UV-Visible - Perkin Elmer make model Lambda 35, FT-IR - Perkin Elmer make Model Spectrum RX1 and Reversed phase High Performance Liquid Chromatography (SHIMADZU-JAPAN) with ODS - C18 as main column and a guard column of Shim-Pack G-ODS were used.

\section{Grafting of MCT- $\beta-C D$ on fabric}

The grafting of MCT- $\beta-C D$ was based on previously reported method ${ }^{16}$. The reaction parameters are optimized as per Table- 1 to get higher percentage of MCT- $\beta$-CD and the optimized condition was applied for permanent fixation of MCT- $\beta$-CD on bulk material. Fabric (M1) was soaked in an aqueous solution containing 10\% MCT- $\beta-C D(v / v)$ and $10 \%$ sodium carbonate $(\mathrm{w} / \mathrm{v})$ in 1:20 material liquor ratio under magnetic stirring at room temperature. Samples were squeezed to get wet pick up of $70-80 \%$ then dried at $80^{\circ} \mathrm{C}$ to prevent the hydrolysis of MCT moiety and cured in hot air oven at $150^{\circ} \mathrm{C}$ for 5 minutes at atmospheric pressure. Fabric was repeatedly washed with de-ionized water to remove the excess of alkali and MCT- $\beta-C D$ and dried to get the modified fabric (M2). The fixation yield of MCT- $\beta-C D$ was estimated by the weight difference of the fabric before and after the fixation process.

Table 1. Optimization of parameters for fixation of MCT- $\beta$-CD on fabric.

\begin{tabular}{llc}
\hline S.No & Fixed Parameters & Variable Parameter \\
\hline 1 & $\mathrm{P} 2=10 \%, \mathrm{P} 3=150^{\circ} \mathrm{C}, \quad \mathrm{P} 4=5 \mathrm{~min}$ & $\mathrm{P} 1=2,4,6,8,10,12 \& 14 \%$ \\
2 & $\mathrm{P} 1=10 \%, \mathrm{P} 3=150^{\circ} \mathrm{C}, \mathrm{P} 4=5 \mathrm{~min}$ & $\mathrm{P} 2=2,4,6,8,10,12 \& 14 \%$ \\
3 & $\mathrm{P} 1=10 \%, \mathrm{P} 2=10 \%, \quad \mathrm{P} 4=5 \mathrm{~min}$ & $\mathrm{P} 3=100,120,140,160,180 \& 200^{\circ} \mathrm{C}$ \\
4 & $\mathrm{P} 1=10 \%, \mathrm{P} 2=10 \%, \quad \mathrm{P} 3=150^{\circ} \mathrm{C}$ & $\mathrm{P} 4=2,4,6,8,10 \& 12 \mathrm{~min}$ \\
\hline (P1= Conc of MCT- $\beta-\mathrm{CD}, \mathrm{P} 2=\mathrm{Conc}$ of sodium carbonate, $\mathrm{P} 3=$ Temperature, $\mathrm{P} 4=$ Time $).$
\end{tabular}




\section{Fixation of Thymol on Fabrics}

The fixation of thymol on fabric was based on the literature ${ }^{9}$. Fabrics M1 and M2 were treated with thymol by soaking separately in 5\% thymol in ethanol/water (60:40) mixture and magnetically stirred at $40^{\circ} \mathrm{C}$ for 2 hours. Fabric was squeezed, washed with ethanolwater mixture (30:70) and running tap water to remove unloaded thymol from fabric surface and dried. Thymol loaded fabrics were designated as thymol loaded unmodified fabric (M3) and thymol loaded modified fabric (M4).

\section{Extraction of thymol and HPLC analysis}

Thymol extraction and its HPLC analysis were done based on the literature ${ }^{9}$. Thymol was extracted from fabrics by treatment with $10 \mathrm{ml}$ of ethanol at $70^{\circ} \mathrm{C}$ under magnetic stirring for 20 minutes. The process was repeated three times with $10 \mathrm{ml}$ of ethanol. Extract was condensed to $10 \mathrm{ml}$ and HPLC analysis was done to quantify thymol.

\section{Testing of fabrics for antibacterial activity}

Thymol loaded fabrics (M3 \& M4) were tested for gram positive bacteria (S.aureus ATCC 11632) and gram negative (E.coli ATCC 10536) by qualitative measurement using agar diffusion test. Fabric was spread over the centre of nutrient agar plate inoculated with bacterial cells for intimate contact. The plates were then incubated at $37^{\circ} \mathrm{C}$ for 24 hours. The inhibition was assessed from the zone developed in and around the fabric. The durability of antibacterial finishing was investigated by performing the same test after each cycle of washings with $2 \mathrm{gpl}$ of soap at $60^{\circ} \mathrm{C}$ for 10 minutes.

\section{Results and Discussion}

\section{Evaluation of MCT- $\beta$-CD fixation on fabric}

The effect of variants on fixation yield of MCT- $\beta-C D$ is depicted in Figure 1 (a, b, c \& d). The yield is assessed from the weight gain of the fabric. When MCT- $\beta$-CD concentration is raised a linear increase in weight of modified fabric occurred up to $10 \%$, thereafter slight decrease occurs due to the hydrolysis of excess MCT- $\beta$-CD. Sodium carbonate is influencing the fixation up to $10 \%$ above which it decreases due to hydrolysis of MCT- $\beta$-CD at higher $\mathrm{pH}$. Temperature influences the MCT- $\beta-\mathrm{CD}$ fixation on fabric but higher temperature damages the fabric. Hence a suitable temperature of $150^{\circ} \mathrm{C}$ is used for the reaction. Heat treatment effect is enacted by time of treatment. Long duration of treatment at higher temperature above $150^{\circ} \mathrm{C}$ damages the fabric and increases yellowness. Therefore, six minutes is sufficient to get desirable result. A considerable yield of 5-6\% is obtained by using $10 \%$ MCT- $\beta-\mathrm{CD}, 10 \%$ sodium carbonate, $150^{\circ} \mathrm{C}$ temperature and 5 minutes of treatment time.

\section{Characterization of fabric}

UV- Visible spectrum is depicted in Figure 2. Organic cotton (A) shows no absorption maximum between $200-400 \mathrm{~nm}$. MCT- $\beta-C D$ (B) represents absorption maximum at $230 \mathrm{~nm}$ corresponding to triazine nucleus. Alcoholic solution of thymol (C) and thymol treated unmodified fabric (D) exhibits absorption at $272 \mathrm{~nm}$ characteristic of $\pi-\pi^{*}$ of benzene ring and phenolic -OH group. Thymol loaded modified fabric (E) represents absorption maximum at higher wavelength $276 \mathrm{~nm}$ due to the inclusion of thymol into hydrophobic cavity of MCT $-\beta-C D$ and another peak at $229 \mathrm{~nm}$ characteristic of triazine moiety. 

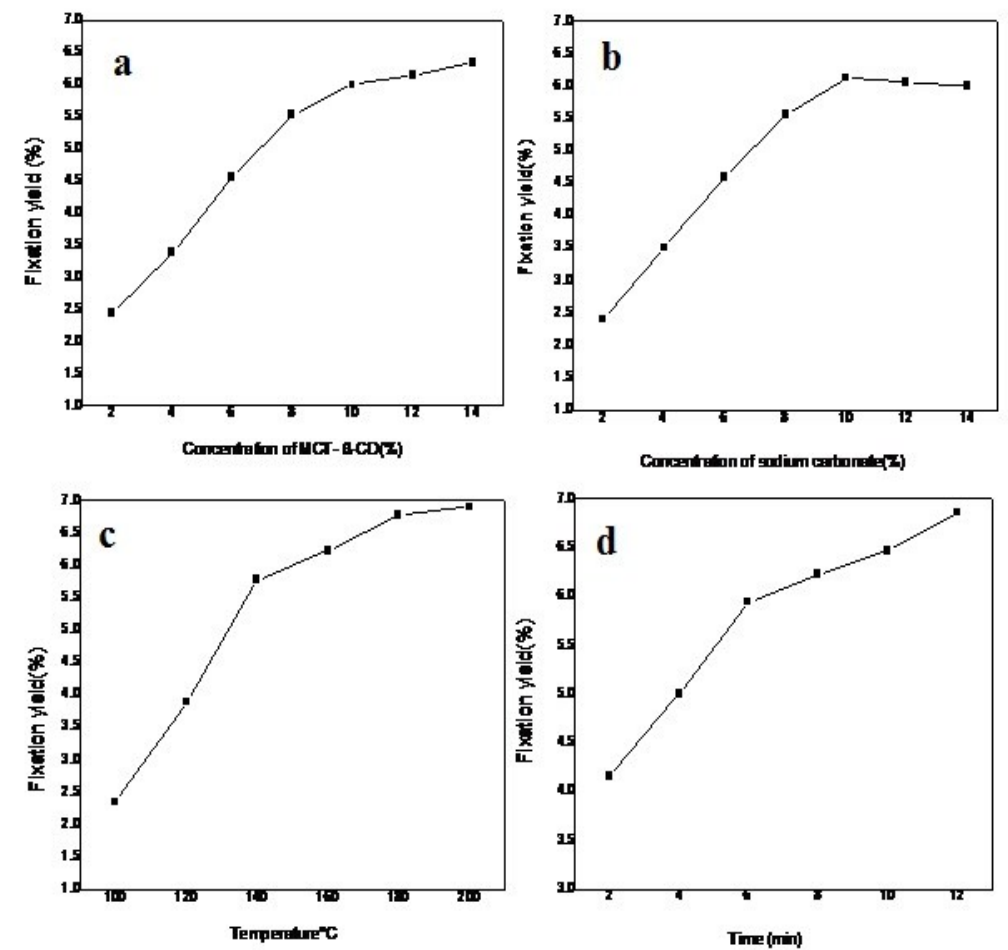

Figure 1. Effect of parameters a) Concentration of MCT- $\beta-C D, b)$ Concentration of $\left.\mathrm{Na}_{2} \mathrm{CO}_{3}, \mathrm{c}\right)$ Temperature, d) Time on fixation of MCT- $\beta-\mathrm{CD}$.

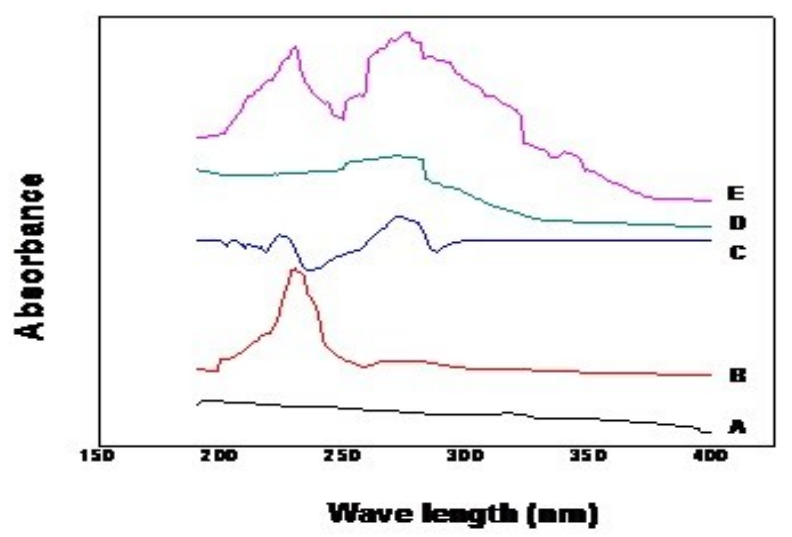

Figure 2. UV-Visible spectra of (A) Organic cotton, (B) MCT- $\beta$-CD, (C) Thymol, (D) Thymol treated unmodified fabric (E) Thymol loaded modified fabric.

FT-IR spectra of the samples are depicted in Figure-3. Organic cotton (A) shows a broad peak at $3347 \mathrm{~cm}^{-1}$ corresponding to $-\mathrm{OH}$ stretching vibration of cellulose. Asymmetric 
stretching of $\mathrm{C}-\mathrm{H}$ is observed at $2890 \mathrm{~cm}^{-1}$ and a sharp peak of $-\mathrm{OH}$ bending of cellulosic fabric occurs at $1630 \mathrm{~cm}^{-1}$ respectively. The spectrum of MCT- $\beta-C D$ (B) shows -OH stretching of cyclodextrin moiety at $3358 \mathrm{~cm}^{-1}$ and $\mathrm{C}-\mathrm{H}$ stretching at $2921 \mathrm{~cm}^{-1}$. The stretching vibration of $-\mathrm{C}=\mathrm{N}$ and $\mathrm{C}-\mathrm{Cl}$ groups of MCT $-\beta-\mathrm{CD}$ moiety occurs at $1574 \mathrm{~cm}^{-1}$ and $690 \mathrm{~cm}^{-1}$ respectively. The MCT- $\beta-C D$ modified fabric (C) is not exhibiting band characteristic of $\mathrm{C}-\mathrm{Cl}$ stretching vibration, because the chlorine atom is removed when covalently bonded to cotton. Thymol spectra (D) show a broad band at $3406 \mathrm{~cm}^{-1}$ corresponds to $-\mathrm{OH}$ stretching of phenolic group. The aromatic character of phenolic compound was exhibited by $-\mathrm{C}=\mathrm{C}$ stretching of benzene ring at $1625 \mathrm{~cm}^{-1}$. Peaks at 1360 and $1222 \mathrm{~cm}^{-1}$ corresponds to $-\mathrm{OH}$ bending and $\mathrm{C}-\mathrm{O}$ stretching of phenolic group. Thymol loaded modified fabric (E) produce $-\mathrm{OH}$ stretching vibration of phenolic group at $3390 \mathrm{~cm}^{-1}$ respectively.

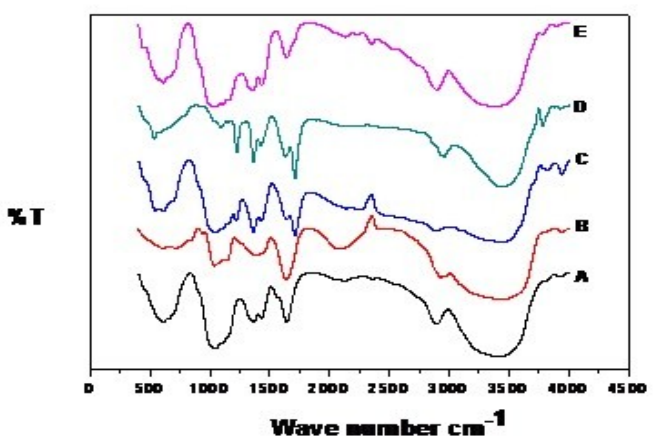

Figure 3. FT-IR spectra of (A) Organic cotton, (B) MCT- $\beta$-CD, (C) MCT- $\beta$-CD modified fabric (D) Thymol (E) Thymol loaded modified fabric.

\section{Quantification of thymol on fabric}

Alcoholic extract of thymol obtained from fabrics M3 and M4 are subjected to HPLC analysis and their thymol content is found to be $0.018 \%$ and $0.471 \%(\mathrm{w} / \mathrm{w})$ respectively. Fabric (M3) has low thymol content; because thymol is neither incorporated nor chemically bonded to fabric (M3) therefore it is easily washed away. MCT- $\beta$-CD modified fabric (M4) has high percentage of thymol due to the inclusion complex formation ability of cyclodextrin moiety with thymol by the way it is protected during washing process.

\section{Antibacterial properties of fabric}

Antibacterial activity of fabrics is depicted in Figure 4 (A, B, C \& D). Thymol has more bactericidal action towards E.coli. Antibacterial effect is much more in thymol loaded modified fabric (M4) than that of fabric (M3). The zone of inhibition is depicted in Table-2. When thymol is present as inclusion complex within the cavity of cyclodextrin moiety of MCT- $\beta-C D$, it exhibits the antibacterial effect much better than its presence as physically adsorbed material on the surface. Fabric (M3) is not able to withstand antibacterial property for more number of washing cycles, because the absorbed thymol passes away during each cycle of washings and at last the activity almost vanishes on the fabric. In modified fabric (M4) thymol is secluded into cyclodextrin cavity; hence it is capable to with stand the repeated washing cycles. 

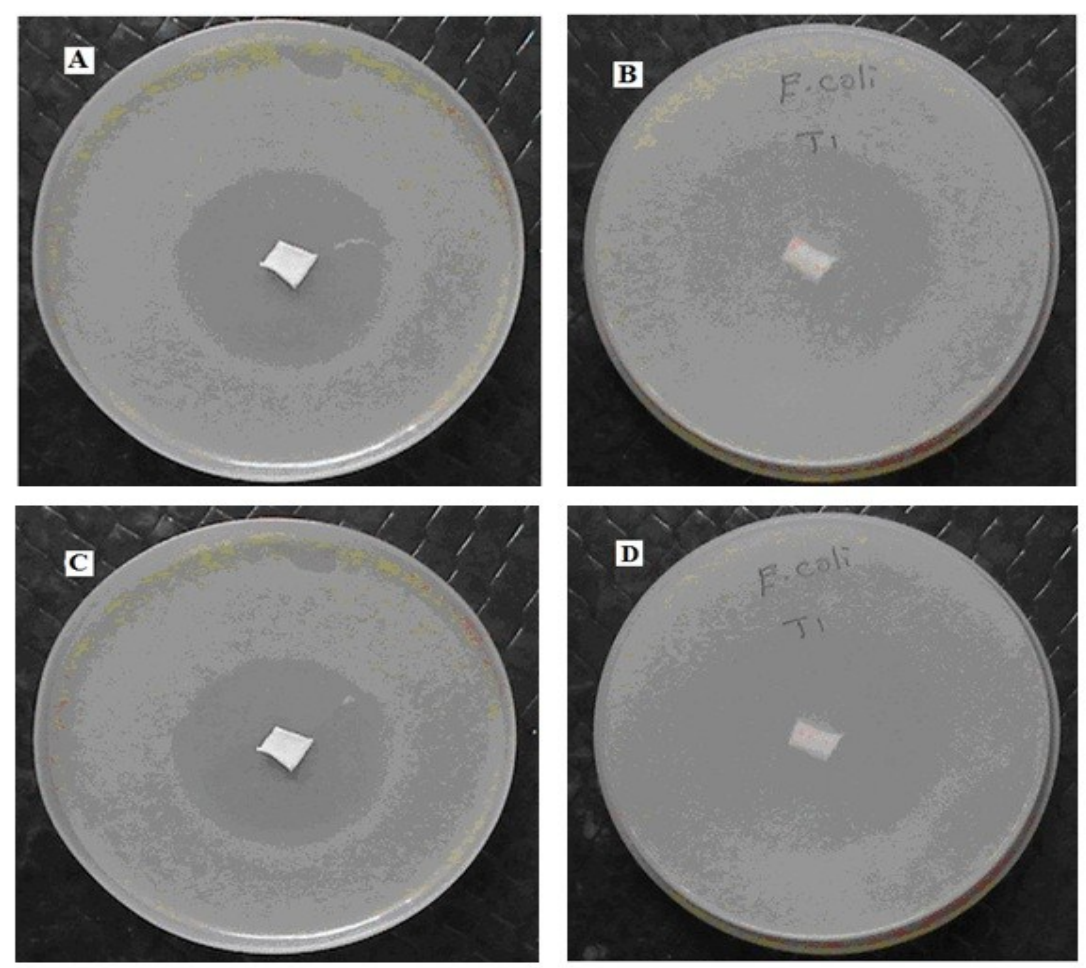

Figure 4. Antibacterial property against S.aureus and E.coli for (i) Thymol treated unmodified fabric (A, B) (ii) Thymol loaded modified fabric (C, D).

Table 2. Antibacterial properties of fabrics against microorganism.

\section{Zone of inhibition (mm)}

Contents

Unmodified fabric(M3) Modified fabric(M4)

\begin{tabular}{lcccccc} 
Washing cycles & 0 & 5 & 10 & 0 & 5 & 10 \\
S.aureus & 29 & 7 & 0 & 35 & 32 & 30 \\
& & & & & & \\
E.coli & 33 & 12 & 0 & 43 & 40 & 37 \\
\hline
\end{tabular}




\section{Conclusions}

Durable antimicrobial finishing of textile was done by permanent fixation of MCT- $\beta$-CD under alkaline condition. Thymol was loaded on fabric and UV-Visible, FT-IR spectral analysis confirmed the chemical bonding of MCT- $\beta-C D$ to fabric. HPLC proved the higher percentage of thymol in fabric M4. The inhibition effect and washing durability of fabrics towards S.aureus and E.coli proved that modified fabric (M4) exhibited pronounced inhibition effect in all washing cycles. Among the two bacteria, E.coli's growth is highly restricted by the special features of thymol. Hence incorporation of any active agents into cyclodextrin moiety of MCT- $\beta-\mathrm{CD}$ modified fabric could produce a durable antibacterial finish to textiles.

\section{References}

1. Reusher H, Hinsenkorn R, J. Incl. Phenom. Mol Recogn.Chem., 1996, 25, 191.

2. Lo Nostro P, Fratoni L, Ridi F and Baglioni P, J. Appl Polym Sci., 2003, 88, 706.

3. Voncina B, Majcenle Marechal A, J. Appl Polym Sci., 2003, 96, 1323.

4. Lu J, Hill M A, Hood M D F, Greeson J R, Horton P E, Orndorf A S, Tonelli A E, J of Appl polym Sci., 2001, 82, 300.

5. Nostro P L, Fratoni L, Baglioni P, J.Inclusion phenom. Macrocyclic Chem., 2002, 44, 423.

6. Romi R, Nostro P L, Bocci E, Ridi F, Baglioni P, Biotechnol. Prog., 2005, 21, 1724.

7. Ibrahim N A, Refai R, Youssef M A, Ahmed A F, J. App.l polym sci., 2005, 97, 1024 .

8. Gawish S M, Ramadan A M, Mosleh S, Morcellet M, Martel B, J.Appl. polym sci., 2006, 99, 2586.

9. Scalia S, Tursilli R, Bianchi A, Lo Nostro P, Bocci E, Ridi F, Baglioni P, International Journal of Pharmaceutics, 2006, 308, 155.

10. Wang J H, Cai Z S, Carbohydrate polymer, 2008, 72, 695.

11. Sricharussin W, Journal of the Textile Institute, 2009, 100, 682.

12. Hebeish A, Shafei E L, Shaarawy S, Polymer plastics Technology and Engineering, 2009, 48, 839.

13. Montazer M, Jolaei M M, Journal of the Textile Institute, 2010, 101, 165.

14. Liang J, Chem Y, Ren X, Barnes R, Wu K, Worley S D, Broughton R M, Cho U, Kocer H, Huang T S, Ind. Eng. Chem. Res., 2007, 46, 6425.

15. Cosentino S, Tuberoso C I, Letters in Applied microbiology, 1999, 29, 130.

16. Lo Nostro P, Frantoni L, Ridi F, Baglioni P, J. Appl. Polym. Sci., 2003, 88, 706. 


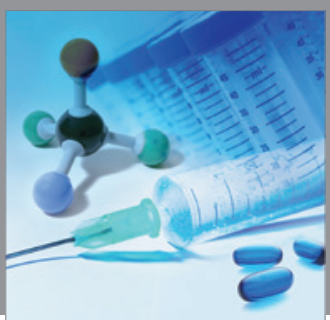

International Journal of

Medicinal Chemistry

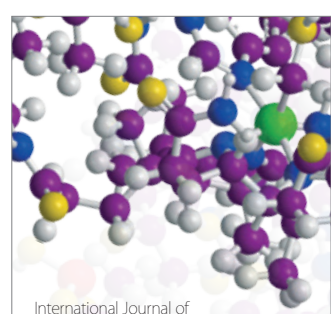

Carbohydrate Chemistry

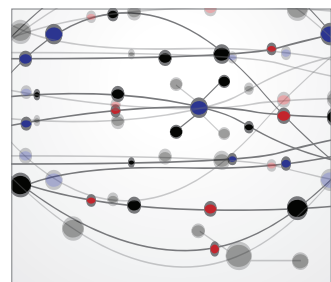

The Scientific World Journal
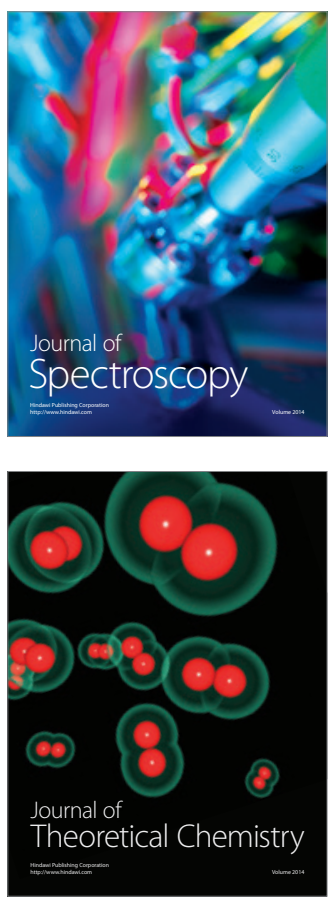
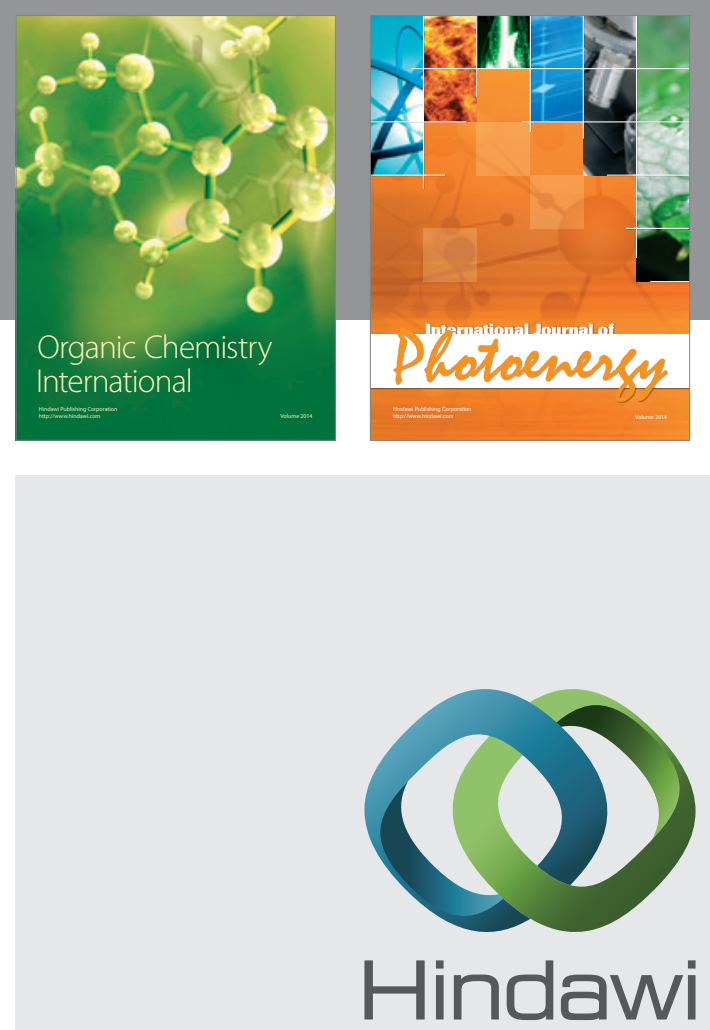

Submit your manuscripts at

http://www.hindawi.com
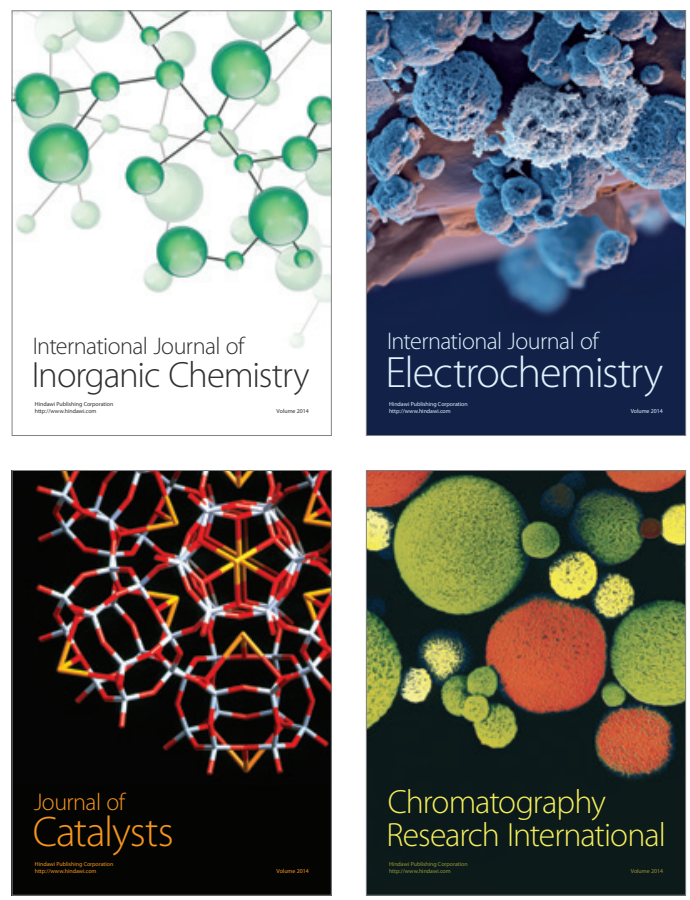
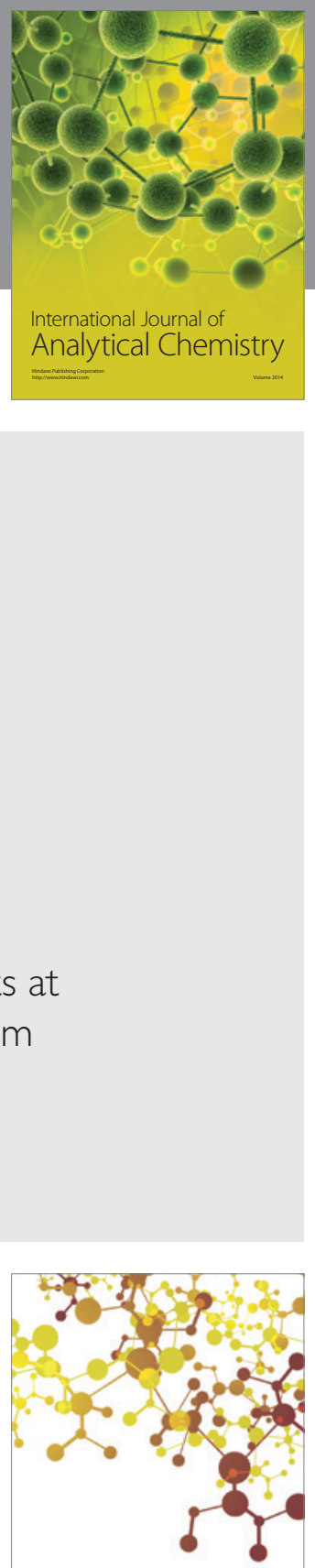

Journal of

Applied Chemistry
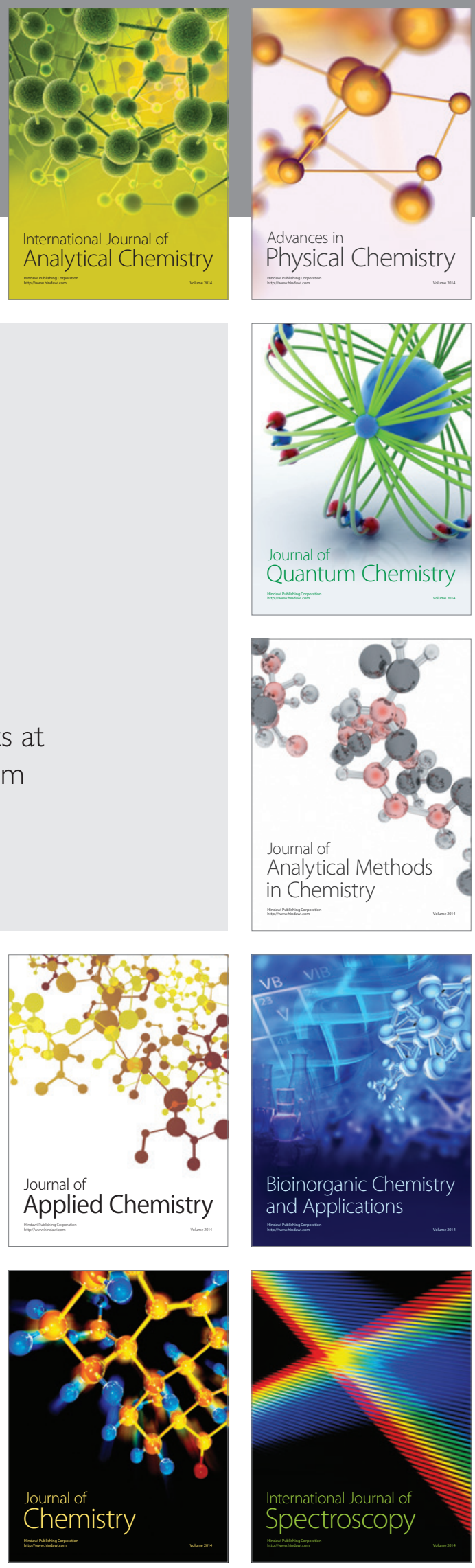